\title{
Remote workers' experiences with electronic monitoring during Covid-19: implications and recommendations
}

\author{
Debora Jeske \\ School of Applied Psychology, University College Cork, Cork, Ireland \\ Received 26 February 2021 \\ Revised 30 September 2021 \\ 20 November 2021
Accepted 18 January 2022

Effects of electronic monitoring

\begin{abstract}
Purpose - This conceptual article outlines the known effects of employee monitoring on employees who are working remotely. Potential implications, as well as practitioner suggestions, are outlined to identify how practitioners can create more supportive employee experiences as well as apply these to workplace health management scenarios.

Design/methodology/approach - This overview is based on a selective and practically oriented review of articles that hitherto considered the health implications of remote workers being monitored electronically over the last two years. This overview is subsequently complemented by a discussion of more recent findings that outline the potential implications of monitoring for remote employees, employees' work experience and workplace health management.

Findings - Several practitioner-oriented suggestions are outlined that can pave the way to a more supportive employee experience for remote workers, who are monitored electronically by their employers. These include the various health and social interventions, greater managerial awareness about factors that influence wellbeing and more collaboration with health professionals to design interventions and new workplace policies. Organizations would also benefit from using audits and data analytics from monitoring tools to inform their interventions, while a rethink about work design, as well as organizational reviews of performance and working conditions further represent useful options to identify and set up the right conditions that foster both performance as well as employee well-being.

Originality/value - The article outlines practitioner-oriented suggestions that can directly and indirectly support employee well-being by recognizing the various factors that affect performance and experience.
\end{abstract}

Keywords Employee monitoring, Remote work, Mental health, Well-being, Pandemic

Paper type Viewpoint

\section{Introduction}

Over the course of the last 20 years, many employers have increasingly experimented with remote working. As the number of freelancers and gig workers rose, coinciding with the expansion of online platforms, more and more individuals have started to work from home. This trend was mirrored in education as more and more private companies and public sector institutions started to move educational content and entire programs online. Prior to the pandemic, $15 \%$ of employees worked from home in the USA according to a survey by Brandon Hall Group (2020). This matches other studies in Germany (Groll, 2019). In 2020, the pandemic forced entire industries to explore and in part adopt remote working where possible. This has pushed up the number of remote workers in some companies and industries to $75 \%$ and higher (Brandon Hall Group, 2020). And many employees and employers in different countries expect that remote working arrangements will become the

(C) Debora Jeske. Published by Emerald Publishing Limited. This article is published under the Creative Commons Attribution (CC BY 4.0) licence. Anyone may reproduce, distribute, translate and create derivative works of this article (for both commercial and non-commercial purposes), subject to full attribution to the original publication and authors. The full terms of this licence may be seen at http:// creativecommons.org/licences/by/4.0/legalcode

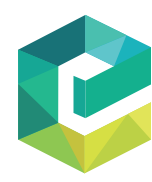


IJWHM

15,3

established and more prominent work option following the pandemic than in previous decades for many office workers (Brandon Hall Group, 2020; Wandt, 2020).

These developments have also spawned new papers on the topic of working from home, the need to accommodate virtual teamwork and leadership (e.g. Koekemoer et al., 2021) and the importance of establishing organizational norms for this form of work (Kniffin et al., 2021). Furthermore, many researchers have noted that aspects such as employee experience considering health and well-being - require more consideration in the future (Kniffin et al., 2021; Sinclair et al., 2020). Fortunately, a great number of resources and insights have been generated over the last few years in areas such as international human resource (HR) research and workplace health management that can readily support such efforts (Blanchard et al., 2009; Caligiuri et al., 2020; Carnevale and Hatak, 2020; Justesen et al., 2017; Martin et al., 2016, 2018; Mellor and Webster, 2013; Tomczak et al., 2018).

Indeed, over the last two years, we have seen the increasing adoption of $\mathrm{HR}$ and communication tools to monitor and manage employees working from home. The emergence, popularity and increasing use of new tools that are installed and running on our work devices mean that employers are now in a situation that grants them a direct "line of sight" and minuteby-minute record concerning everything that their remote employees are doing during work hours (Allyn, 2020; Hern, 2020; Hill, 2020). Of course, some employers have used productivity analytics and employee monitoring on production sites and in offices for decades to keep track of production, monitor performance quality and manage potential risks in the workplace (Jeske, 2021). The emergence of new situational stressors and constraints due to the sudden move to remote working (Bolisani et al., 2020) and limitations caused by lockdowns (and homeschooling for many working parents; Anderson and Kelliher, 2020), in combination with the increasing adoption of new employee monitoring tools in 2020 (Hern, 2020; Morrison, 2020), has created a maelstrom of challenges, which are causing strain for many remote workers (e.g. Passetti et al., 2021; Kalischko and Riedl, 2021; Welter and Ensslin, 2021).

This viewpoint article first outlines the known effects of employee monitoring on employees and the potential effects that might emerge for those who are working remotely. The second part of the article focuses on the potential implications as well as practitioner suggestions, which identify how health professionals and practitioners can, together with other stakeholders within their organizations, create more supportive employee experiences as well as connect these to workplace health management. In order to understand the issues around electronic performance monitoring, the next section outlines some of the prepandemic findings about electronic monitoring that demonstrates our current knowledge about the antecedents and effects of electronic monitoring more generally (Jeske, 2021; Jeske and Santuzzi, 2015; Ravid et al., 2020; Yost et al., 2019). These findings are complemented by insights gained about the employee experience during 2020 and 2021. The focus here is specifically placed on practice-relevant insights and the identification of potential implications for workplace health management, as a result of electronic performance monitoring within organizations. While this contribution focuses predominantly on the experiences of employees that have the option to work remotely - a smaller proportion of the working population in most countries (Baker, 2020) - some of these insights and potential implications may also be relevant for the management and support of on-site employees.

\section{Electronic monitoring at work: known effects}

Electronic monitoring has been a regular feature in many factory shop floors and offices for decades. Monitoring can be distinguished in terms of its purposes, invasiveness, synchronicity (which may allow for frequent, continuous and instantaneous recording) and the transparency of their use and deployment (Jeske and Santuzzi, 2015; Ravid et al., 2020). Electronic monitoring and its effects have been explored and summarised in many different studies and practitioner reports in recent times prior to the pandemic 
(e.g. Abraham et al., 2019; Bernstrøm and Svare, 2017; Indiparambil, 2019; Martin et al., 2016; Ravid et al., 2020; Tomczak et al., 2018). The increase in monitoring was further accelerated in numerous countries due to the start of the pandemic in 2020 as many employers across the world adopted remote working practices (e.g. Allyn, 2020; Gustavsson and Söderlund, 2021; Hill, 2020; Passetti et al., 2021). In addition to this body of work, many researchers focused on aspects such as technostress and performance (Atanasoff and Venable, 2017; Laird et al., 2018; Spagnoli et al., 2020), recognizing the role of how technology can impact individual health and wellness as well as organizational outcomes. A critical component for the employee experience is the purpose that drives the use of electronic performance monitoring (Ravid et al., 2020). Two purposes are particularly relevant for practitioners in the workplace health domain because they also carry the potential to affect employee experience, attitudes and emotions negatively or positively (Welter and Ensslin, 2021).

The first of these motives for the implementation of such monitoring is to reduce costs and risks (Adams, 2013; Welter and Ensslin, 2021). In this case, monitoring is used a means to exercise more control over employees' performance in the organization (e.g. Adams, 2013; Bartels and Nordstrom, 2012; Shaffer and Darnold, 2020; Siegel et al., 2021), an aspect that also became more prominent around the world in numerous countries as work moved online due to the pandemic (e.g. Blumenfeld et al., 2020; Gustavsson and Söderlund, 2021; Passetti et al., 2021). This approach is often based on the assumption employees cannot be trusted to act in the best interest of the company and should be tightly monitored to ensure that the business is getting the maximum return on investment (Hill, 2020), a standpoint more in line with digital Taylorism (Wang et al., 2020). Such a mindset often leads to decision-making that excludes employees from having any say in the adoption of monitoring or the invasiveness, regularity and pervasiveness of the monitoring (see also Vatcha, 2020). For example, close and continuous monitoring is often interpreted as reflecting a lack of trust on behalf of management (Allyn, 2020; Jamal et al., 2021). New tools will often generate new issues due to a poor fit with the prevailing culture, organizational characteristics, shared values and norms (Tomczak et al., 2018). Indeed, higher levels of perceived surveillance and coercive control have been linked to more counter-productive work behaviors (Martin et al., 2016; Shaffer and Darnold, 2020; Tomczak et al., 2018), that is, voluntary or intentional behaviors, which are not in the interest the organization (Chang and Smithikrai, 2010). Moreover, new concerns on the side of employers arise due to the demotivation of employees (Martin et al., 2016; McEvoy, 2020), and the emergence of negative attitudes and poorer performance of teams (e.g. team cohesion and collaboration reduces when team members are individually monitored and team contributions are no longer captured; see also Welter and Ensslin, 2021). Monitoring can therefore trigger resistance to monitoring and conflicts between employees and management (Alge and Hansen, 2014; Bathini and Kandathil, 2020; Wang et al., 2021).

The second motive for the implementation of monitoring is to increase performance and identify room for development (Ravid et al., 2020; Tomczak et al., 2018). For example, many employers use monitoring tools to access dashboards that visualize processes, enabling them to assess workflow and delays (Blumenfeld et al., 2020; Jeske, 2021). This can create more transparency and help employees to focus on core tasks (Wang et al., 2021). In those instances, these tools enable managers to proactively support employees and share timely developmental feedback with individuals and teams to help them optimize their performance (ideally supplemented by appropriate training interventions; Tomczak et al., 2018). This transparency, combined with employee consent, can help to maintain perceived fairness and justice (Tomczak et al., 2018). The key here is that employees feel trusted (Bernstrøm and Svare, 2017; Rees, 2020) and retain some degree of autonomy, an aspect that has become important to many remote workers during the pandemic (Bathini and Kandathil, 2020; Jamal et al., 2021). This motive has also sparked more interest in how future monitoring systems should be designed in recognition of the ethical, cultural and privacy concerns (e.g.
Effects of electronic monitoring 
IJWHM

15,3

396

Kalischko and Riedl, 2021; Sherif et al., 2021). Employers who emphasize trust and appreciation are far more likely to set up the monitoring in a way that meets rather than undermines employees' needs, such as the need for belonging, co-determination and trust (see also Tomczak et al., 2020, on the impact of monitoring on the psychological contract). Indeed, the "employees' feeling of trust increases with the level of control over decisions at work and decreases relative to the level of monitoring at work" (Bernstrøm and Svare, 2017, p. 43). Such positive effects can be fostered if employees are able to voice their concerns, participate in the design of the tool and the setting of standards as well as the identification of appreciation and recognition means and appropriate tool training (Laird et al., 2018; Kalischko and Riedl, 2021; Martin et al., 2016). As a result, employee reactions to electronic monitoring are often influenced by the motives behind the implementation of the monitoring systems, the use of these systems and the extent to which employee needs are met and their voices heard (by the organizations and managers who are directly responsible for systems implementation).

\section{Remote working plus electronic monitoring during Covid-19: emerging insights} The importance of workplace health management in the monitored workplace becomes apparent when we reflect on the number of situational challenges that have arisen due to Covid-19, as well as the personal pressures on employees that emerged as a result of the pandemic and employer decision-making on how to manage performance (e.g. Sinclair et al., 2020). Relevant peer-reviewed scholarly articles were identified using several keywords, usually in combination, such as "electronic monitoring," "electronic performance monitoring," "pandemic", "Covid-19”, "remote work," "health management” and "employee health", using databases such as Emerald, Springer, Wiley and Google Scholar. The literature search focused on work published between January 2020 and September 2021. The next section describes general employees' work experience and identifies a number of challenges, which can trigger new or exacerbate existing mental and physical health issues.

In the context of Covid-19, many employees experienced a number of challenges. Many were suddenly sent home with minimal workplace provisions to accomplish their work remotely. Parents often ended up at home-schooling their children during lockdowns, creating significant levels of social strain, stress and work interruptions (APA, 2020; Zhou et al., 2020). Access to everyday resources was restricted in many locations. Many individuals were physically isolated, reducing their interpersonal support network outside the workplace during the pandemic. Other issues reported in 2020 concerned increased work-life conflict, anxiety, financial concerns and an unequal workload allocation that disadvantaged parents more often, particularly women (e.g. Eurofound, 2020; Mallett et al., 2020).

The introduction of new tools to monitor employees in their homes during work hours added another facet to already challenging everyday lives (Aloisi and De Stefano, 2021; Vatcha, 2020; Blumenfeld et al., 2020). Many employees needed to manage multiple demands on their time simultaneously; this included the need to learn new technologies, readjust to working in shared and private spaces at home and managing the challenges of both work and home demands (CIPD, 2020; Wang et al., 2021). This triggered a cascade of undesirable consequences related to workflow interruptions and work-life conflict, which, in turn, can be seen to contribute to emotional exhaustion, job and performance dissatisfaction (Baethge and Rigotti, 2013; Cho et al., 2020; Pachler et al., 2018; Wang et al., 2021). These circumstances are further compounded for many remote workers by the extensive use of work reminders issued by most electronic monitoring tools (Allyn, 2020). The introduction of continuous and often video-based monitoring, akin to a "pandemic panopticon" (Aloisi and De Stefano, 2021), has further increased remote workers' concerns about the invasions of one's privacy while working at home (Hern, 2020; Vatcha, 2020). This means that the introduction and intensive use of monitoring has created an intractable situation for many employees, which results in 
less employee voice and raises more concerns about being made redundant (Allyn, 2020; CIPD, 2020).

The outcomes of work intensification via high-performance work systems, which also includes electronic monitoring systems (see Shaffer and Darnold, 2020), on employees' wellbeing are well known (Chillakuri and Vanka, 2021; Wang et al., 2021). The most recent evidence gathered during the pandemic would suggest that employee monitoring increases the tendency towards presenteeism among on-site and remote workers, a trend that has now become a prominent concern for many remote workers over the world (e.g. Bathini and Kandathil, 2020; Bulińska-Stangrecka et al., 2021; Sinclair et al., 2020). Indeed, many employees in 2020 worked longer, not shorter, work hours (Bolisani et al., 2020; DeFilippis et al., 2020; Rees, 2020) and experienced a significant increase in work intensification due to home working (Mallett et al., 2020). Closely monitored employees often fear punitive consequences, report stress and emotional exhaustion (Baer et al., 2015; Tavani, 2004). Monitored employees often report high tension and anxiety (Indiparambil, 2019), but also negative attitudes and emotions (Shaffer and Darnold, 2020). The inevitable outcomes are an increase in errors that may delay projects further, leading to underperformance due to exhaustion, and the adoption of undesirable work practices due to fatigue (Cheng et al., 2020; Martin et al., 2018) as well as counterproductive work behaviors; see also Shaffer and Darnold (2020). As a result, "occupational health and medicine" has become an important issue in the pandemic work environment (Sinclair et al., 2020). Several interventions can be helpful to address the work-related stress symptoms of remote workers, including those who are monitored electronically. These are outlined in the next section.

\section{Supporting monitored remote workers: practitioner-oriented suggestions}

The pandemic has created a situation where the expertise of health professionals is more critical than ever before (Sinclair et al., 2020). Prior to the pandemic, crisis management was rarely a priority in the HR development domain (Sarmah and Chaudhuri, 2021), a domain that has been criticized for failing to research and tackle many of the current issues relevant to the modern workplace (Bierema, 2020). Though many specialists and HR development practitioners were quick to respond to the pandemic with crisis management interventions (see approach by Arora and Suri, 2020), professionals in health and safety, occupational health and emergency medicine were and still often have more experience when it comes to the employment of both crisis and health-promoting interventions. As a result, many organizations seek advice on how to effectively implement health-promoting interventions and new workplace policies (Jeffery, 2020), in addition to pandemic-related support with health and safety initiatives in the workplace.

Several options exist for health management professionals, in collaboration with HR experts and managers, to improve the work experience and well-being of remote employees that are monitored electronically (see also Sinclair et al., 2020; Wang et al., 2021). The following sections outline different opportunities and approaches that can complement, and enrich, existing health management options and inform future people management practice.

\section{Health-promoting and social support interventions}

Given the adoption of digital apps and online employee assistance programs, there is moreover no shortage of options and resources available to support employees who work remotely when this is necessary (e.g. National Safety Council, 2021; Pierce et al., 2021). During the pandemic in 2020 and 2021, many employers rolled out new health-promoting digital wellbeing programs for their remote workers (Wyatt, 2020). In addition, some recent research has informed specific guidance on behavioral interventions that can help to improve the health of remote workers (e.g. Bartmann et al., 2022). As a result, many employers have adopted a
Effects of electronic monitoring 
IJWHM

15,3

variety of different approaches during the pandemic, from online daily live workouts, "Ask the Trainer" Q\&A sessions, "Workout of the Day" videos and weekly live well-being chats with health professionals (Wyatt, 2020). The increasing participation of employees also suggests that such interventions are effective in reaching many more employees than expected due to the flexibility of these new digital offerings (Wyatt, 2020). These trends suggest that it is worthwhile adopting such offerings in the future, particularly if the remote or hybrid mode of working is retained by many organizations to increase the accessibility of health promotion initiatives to remote workers in the future.

While the increased use of digital media for corporate well-being programs is one way to provide health-promoting interventions, the need for other interventions has emerged rather suddenly due to the often-unplanned, transition to home working. One such issue that rose to prominence was the emergence of musculoskeletal disorders reported by many remote workers (e.g. Jain et al., 2021). While some of these issues may have existed prior to the pandemic, working from makeshift offices and ergonomically questionable setups led to a significant increase of such reports (Jain et al., 2021; Ipsen et al., 2021). Digital ergonomics training can now play a significant part in reducing such challenges by increasing employees' awareness of how their posture and work setting in the home will affect their health (Mojtahedzadeh et al., 2021). This too is certainly the case for remote workers who are being monitored continuously as many of these will often sit for long periods of time and have been known to skip breaks to meet task requirements (in line with on-screen presenteeism, see also e.g. Bathini and Kandathil, 2020; Bulińska-Stangrecka et al., 2021).

While employee monitoring can contribute to sedentary behavior due to the pressure to be present in front of various devices, these tools can also generate important insights for health professionals as well as managers. By involving health professionals in the analysis of monitoring data, employers can set appropriate performance standards that enable employees to get the breaks they need and to prevent musculoskeletal as well as visual strain that may arise due to repetitive movements, long-term sedentary work on screen and insufficient breaks (see also Bartmann et al., 2022; Mojtahedzadeh et al., 2021). Given that data is usually collected by electronic monitoring tools about break times and hours worked (and thus also screen time), many health professionals should be able to use this data to also identify potential target groups for interventions such as ergonomic training and corporate well-being programs aimed at improving workers' health and work practices (see also recommendations by Mojtahedzadeh et al., 2021).

Another area of concern for many employers over the course of the pandemic was the increase in psychosomatic and mental health complaints, which are known to increase due to presenteeism and work intensification (Franke, 2015), afflictions which affect many remote workers subject to monitoring (Bulińska-Stangrecka et al., 2021). As a result, many employers revisited, revised and expanded their remote work practices, mental health programs and their work-life balance policies, many of which predated the pandemic (Lockwood and Nath, 2021). However, policies alone were insufficient. Instead, new approaches were needed (DiabBahman and Al-Enzi, 2020). Several suggestions were therefore put forward by health companies as well as health professionals. Raising awareness of mental health is an important first step for many employers to address this followed by meaningful action (e.g. by offering all employees mental health days). As noted by Lyra Health (2020), employee distress and anxiety may not be as readily apparent when everybody works remotely (Lyra Health, 2020). Surveys can provide important insights into the mental health status of the workforce, although it is often difficult to disentangle the impact of work and work conditions on mental health (CIPD, 2020). In addition, aspects such as loneliness, isolation, depression and insomnia are aspects that may not always be apparent to managers, although they seemed to increase among many workers during the pandemic (Bartmann et al., 2022; Jamal et al., 2021; Wang et al., 2021). It is therefore important that there is room for these discussions 
to occur and identify suitable interventions that can be rolled out to all employees, remote or on site.

In addition to offering designated mental health initiatives (such as employee assistance programs, access to in-house health professionals, etc.), another approach here is to offer resilience training to help employees to handle stress and identify effective strategies to cope (a good guide for managers and organizations is the guide by Cooper et al., 2013). However, these approaches may not address mental health issues that are the result of lower perceived social support. The move to working from home reduced the frequency with which many remote workers were able to access social support interactions (Bilotta et al., 2021), a critical buffer for stress (Wang et al., 2021), while the move to the use of monitoring during all work hours further reduced remote workers' time and opportunity to access such social support confidentially or at convenient times during working hours. As a result, working conditions also need to be reviewed (see section below on "Rethinking work design"), as the mere focus on training and interventions aimed at remote workers ignores the role of context variables, such as working and performance conditions.

\section{Managerial insights into and understanding of well-being}

Managers play a critical role in terms of how they employ performance standards, offer individuals and teams social support and create opportunities for training (e.g. Jamal et al., 2021). Above all else, the pandemic revealed the importance and necessity for supportive, health-promoting leadership behaviors (Liu et al., 2021). However, reports about some of the behavior of many managers suggested that they were not fully aware of the positive but also the negative impact they had on their teams (e.g. by enforcing strict performance standards and rolling out very intensive employee monitoring tools, see also critique by Aloisi and De Stefano, 2021). As noted in a recent study of remote workers, both the workload and monitoring being employed essentially function as demands, which end up increasing workhome interference and, in turn, undermined employee well-being (Wang et al., 2021, p. 45). As a result, some researchers noted that many managers need more awareness of how their leadership style, their performance monitoring and feedback practices can directly, as well indirectly (via their use of certain tools), impact employee performance, well-being and health over time (Spagnoli et al., 2020; Wang et al., 2021). This situation is often compounded by the fact that many managers are often unfamiliar with, ill prepared, or uncertain about their role in promoting workplace health (Justesen et al., 2017; Mellor and Webster, 2013). As the last two years have shown, health professionals can and do play an important role in educating employees and managers about time management, boundary setting, health breaks and coping strategies (e.g. Park et al., 2020; Sinclair et al., 2020; Wilkie, 2020; Zhou et al., 2020).

A number of interventions rolled out in different countries over the last two years of Covid19 have demonstrated the importance of upskilling managers, leadership skills and managerial practices to support employees (Bartmann et al., 2022; Dollard and Bailey, 2021; Jamal et al., 2021; Koekemoer et al., 2021). One example here is the importance of training managers to support work stress interventions. Dollard and Bailey (2021) tested the extent to which middle management training could increase the psychological safety climate, that is, the climate that will foster employees' psychological health and prevent harm due to workplace stressors. They observed that such training increased the psychological safety climate over four months during the pandemic in Australia (Dollard and Bailey, 2021).

Another example includes the role of managers in supporting relationship building during onboarding, during meetings and other interactions to increase bonding between people (Bartmann et al., 2022). Role modeling behaviors, such as expressing gratitude, sharing experiences and disclosing, struggle can help remote workers build stronger relationships and enable them to exchange strategies on how to cope with certain challenges (Bartmann et al., 2022). Such activities should not be delegated exclusively to HR and health
Effects of electronic monitoring

399 
IJWHM

15,3 professionals; indeed, managers and leaders can also play an important role in setting up opportunities that allow employees to exchange experiences, learn from one another and promote well-being by fostering a sense of belonging and team cohesion (see also Wang et al., 2021). This may be further facilitated when managers promote and support mindfulness or positive psychology interventions during work time to help employees cope with stress (Bartmann et al., 2022; Dewe and Cooper, 2012).

Awareness campaigns should help managers to coach and support their employees more effectively when they experience stress. Given the popularity of monitoring tools, it is worth noting that many managers now also have access to tools that could allow them to track and analyze employee sentiment (Rees, 2020). This information can be helpful in generating ideas for timely interventions (Al-Hitmi and Sherif, 2018). Such insights can further help health practitioners to time their assistance programs ahead of expected stress peaks (e.g. key sales seasons or seasonal upturns in business operations). In addition, such data use can help managers identify specific target groups and time frames for specific interventions. As became apparent in 2020-2021, Covid-19 peaks occurred at different times in different countries. This also meant that many remote workers were experiencing different restrictions at different times (e.g. lockdowns). In international organizations, this is problematic, impacting the scheduling of interventions. Furthermore, as recent work has shown, cultural differences - both in terms of national and corporate cultures - can play a significant role in predicting the positive adjustment of workers to working from home (Biron et al., 2020), including those who are electronically monitored (Sherif et al., 2021). Awareness of these facets will help managers to identify the needs of their different remote working cohorts, which can, in turn, help them to select suitable models of intervention from mental health initiatives to social interventions.

\section{Rethinking work design}

The challenge of work design to support remote working during the pandemic has therefore become a more prominent concern for many employers (Kane et al., 2021; Mojtahedzadeh et al., 2021; Wang et al., 2021). How work is designed can have a significant effect on the employee experience and thus over time, their performance, motivation, sense of belonging as well as their engagement and commitment (Tomczak et al., 2018; Koekemoer et al., 2021). Important work design factors that need to be considered when it comes to monitoring remote employees include self-direction and self-autonomy in one's work (Aloisi and De Stefano, 2021; Bathini and Kandathil, 2020; Jamal et al., 2021; Wang et al., 2021). Finding the right balance will be critical. Both decision latitude and psychological demands have been shown to effectively mediate the relationship between long work hours and psychological distress (Haines et al., 2012).

When employers decide to implement monitoring, due consideration should be given to best practice that promotes performance (Tomczak et al., 2018; Kalischko and Riedl, 2021) to avoid the "pandemic panopticon" becoming the new normal for remote workers (Aloisi and De Stefano, 2021). Many employers recognize the importance of good work organization, flexibility, autonomy, employee empowerment and control over work for better employee health (Dragano and Lunau, 2020). Yet, these aspects are often cast aside when new tools and work-from-home plans are hurriedly adopted, as was readily apparent during the rapid transit to remote work during the Covid-19 pandemic (see also Aloisi and De Stefano, 2021; Lockwood and Nath, 2021). This is often the case when electronic monitoring is brought in.

Health professionals and counselors understand which kind of control settings and mechanisms may inhibit rather than promote performance for different workers (see also Sinclair et al., 2020). It is therefore advisable that employers are recommended to include these professionals in the implementation phases when adopting new monitoring tools. Such efforts will benefit employers as well as employees as is demonstrated in research that shows 
us that when monitored employees are empowered, they are far less likely to experience the same negative effects of monitoring and will exhibit more positive attitudes and behaviors (Martin et al., 2016). These steps, in combination with health-promoting initiatives in the workplace, increase the changes where employees maintain performance and report higher rates of well-being and morale over the short to long-term (see also Gorgenyi-Hegyes et al., 2021).

Auditing working and performance conditions

Data analytics have become an important topic for many employers. By surveying employees and regularly using data analytics, health professionals and counselors can keep an eye on the pulse of an organization (Lockwood and Nath, 2021). Audits of work conditions and monitoring practices can be helpful (Lockwood and Nath, 2021) in order to gain a better understanding of remote workers' working conditions. Audits are assessments that capture hindering or performance promoting working conditions and assist in devising options to increase technological flexibility and identification of work stressors that can impact employees' adjustment (Blanchard et al., 2009; Koekemoer et al., 2021). Health professionals often have both the insight and tools to support such auditing activities and inform future initiatives by considering employee well-being effects that might arise because of future changes to working and performance conditions - both areas that need more attention.

The need to reassess performance standards is particularly obvious; these are often inherently connected to working conditions (or assumptions about these). While audits are not a new intervention, the need to gain a better understanding of employees' needs has risen in the last two years due to the many personal and situational strains that have arisen for many remote workers. Some employee groups were struggling to work effectively from home. For example, parents working from home while also caring for school age children or vulnerable family members (e.g. Anderson and Kelliher, 2020; Mojtahedzadeh et al., 2021). The rapid move to remote work meant that many employees had to cope with very different and variable working conditions. Many performance standards and rounds were set and designed before the pandemic (O'Connell, 2020; Wigert and Barrett, 2020). Yet, during the early stages of pandemic, many remote workers were subject to the "unforgiving expectations" of their employers (Mallett et al., 2020), with other authors questioning the "short-sightedness of personnel organization policies" (Aloisi and De Stefano, 2021, p. 11). Expecting high performance under extreme and challenging circumstances, such as pandemic-related lockdowns, created significant performance stress for employees, resulting in disengagement over time (O'Connell, 2020; Koekemoer et al., 2021).

By getting feedback from both remote and on-site employees, health professionals can help to identify potential discrepancies regarding the use of monitoring tools for those working at home and those working on site. Such audits can also help to clarify the degree to which uniform performance standards - and performance values - are sustainable and achievable by employees (e.g. such as the tendency to identify and categorize employees into "high performers" or "talent" based on data or old metrics that are likely to be skewed and now taken out of context). This information can help managers to recognize and adjust prepandemic performance expectations and standards (O'Connell, 2020), in line with new situational demands and pandemic performance constraints that may not have been considered in performance rounds hitherto.

Audits can therefore deliver information that can be used to create both performance and work conditions that foster a more manageable balance and a better understanding of mutual needs for both employees and employers. This may be particularly important in the agile workplace as flexible working under Covid-19 has been shown to act as a buffering resource for some workers, while agile working practices can bring about more emotional exhaustion in employee cohorts that are impacted by Covid-19 demands (Koch and Schermuly, 2021). Health

Effects of electronic monitoring 
IJWHM

15,3

professionals can often facilitate such negotiations when they have information from audits that point to certain preferred courses of action. Further, audits can help to identify those employee groups that face the most pressure, such as working parents who are more likely to be leaving their employment in favor of more supportive employers and flexible roles (e.g. Tyler, 2021). Given the increase in turnover reported across many industries and countries in 2021 due stress at work (Gallup, 2021), such audits may be a particularly important in reducing both turnover and stress through the implementation of timely interventions.

Work design is a moving target as situational demands in the workplace continuously change, be that due to pandemic, societal or a combination of technological changes. It is therefore imperative for organizations to really understand monitoring effects when they roll out new monitoring tools for their managers and workforce. Electronic monitoring is a multidimensional phenomenon where context and psychological variables interact in several ways (Ravid et al., 2020). The introduction of new monitoring tools will most certainly require some readjustment, auditing and time to facilitate tool acceptance and ensure that all organizational members know how to appropriately use the monitoring tools and the data thus generated (Al-Hitmi and Sherif, 2018). In terms of monitoring, audits also allow employers to capture information about how new systems affect employees' performance and well-being (see also Wang et al., 2021). Similarly, by identifying and matching cultural and leadership values to the monitoring approach taken (see Abraham et al., 2019; Koekemoer et al., 2021), employers can reduce the likelihood of conflict or lack of fit to established practices. Auditing thus helps employers to assess remote employees' experience and satisfaction with new monitoring tools.

Task-technology fit is a real concern for many employers. For one, continuous electronic monitoring affects how they tackle different tasks and the degree to which they dedicate time to specific tasks (Hill, 2020; Rees, 2020). Second, the introduction of monitoring increases the potential for continuous interruptions, which are known to increase employee exhaustion and irritation (Blanchard et al., 2009; Baethge and Rigotti, 2013), resulting in a feeling of disempowerment (Martin et al., 2016). This means that audits such as the ones proposed above could be an important mechanism to revise the current use case for specific monitoring tools and generate information that actively informs organizational policies. Indeed, having an accurate contextual awareness of the different working conditions, and how the EPM systems interact with these, is essential for setting new workplace guidance (see also Kalischko and Riedl, 2021). Many employers still need to create or update policies that inform employees' expected use of technology (e.g. to avoid presenteeism), guide the managerial use of monitoring tools and set healthy boundaries in order to promote a better work-life balance among remote workers (Jamal et al., 2021; McDaniel et al., 2021). The involvement of health professionals as employee advocates during the creation, and rollout of new workplace policies appears more and more essential (e.g. Diab-Bahman and Al-Enzi, 2020) to ensure that employees' needs and health are heard and appropriately considered in future workplace policies and interventions.

\section{Conclusions}

This viewpoint article provides an overview of findings regarding the effect of electronic monitoring on employee experiences and well-being before and upon the start of the pandemic (e.g. Wang et al., 2021). While close supervision is nothing new at work, the use of new digital tools on employee devices means that in many organizations, employer interests and employee needs at work are set to collide on several fronts. The potential impacts on employees' work experience, stress, performance but also counterproductive behavior at work further highlight the multiple facets that converge in relation to how performance is monitored (Laird et al., 2018; Martin et al., 2016; Yost et al., 2019; Tomczak et al., 2020). 
In addition, future research could add significant insights into new workplace dynamics. More recent evidence that emerged during the pandemic in 2020 provides a starting point to understand how different situational and personal circumstances create new stress and workplace health challenges for many employees working remotely, often from a shared home. These insights generate several new constellations of stress factors. The sudden and often unplanned move to remote working from shared homes has created a maelstrom of challenges for employees (Mojtahedzadeh et al., 2021), a situation that is compounded by the increasing use of electronic monitoring tools, spillover effects and rapid organizational changes (Welter and Ensslin, 2021; Wang et al., 2021).

At the same time, it is also clear that some new questions arise due to combination of knowns and new unknowns. For example, the effects of electronic monitoring on on-site employees at work are well known. However, we are still learning more about the impact of electronic monitoring on remote employees (especially those working from home) during the current pandemic (e.g. Allyn, 2020; Aloisi and De Stefano, 2021; Bathini and Kandathil, 2020; Gustavsson and Söderlund, 2021; Hill, 2020; Passetti et al., 2021; Vatcha, 2020; Wang et al., 2021). Furthermore, the connection of remote work to current workplace health management has largely only been discussed tangentially by professional bodies, practitioners and various news sites (with exception such as Wang et al., 2021).

As a result, there is a significant need for more research on the topic of workplace health management in different workplace settings that are remote, monitored and overlap with one's home environment. That said, health and other professionals can employ a number of practices and utilize different approaches (e.g. work design) to support employees via HR and health-promoting activities even in challenging times. Given this emerging new body of literature (such as Arora and Suri, 2020; Bartmann et al., 2022; Bilotta et al., 2021; Chillakuri and Vanka, 2021; Dollard and Bailey, 2021; Gorgenyi-Hegyes et al., 2021; Kalischko and Riedl, 2021; Kane et al., 2021; Mojtahedzadeh et al., 2021; Sinclair et al., 2020; Wang et al., 2020), health and HR practitioners now have a number of resources to help their organizations to create positive, performance-enhancing, well-being promoting work experiences in the future.

\section{Key insights}

(1) The pandemic increased the adoption of electronic monitoring tools for remote workers in many professions and countries.

(2) Recent evidence suggests that the use of employee monitoring tends to indirectly reduce the well-being of remote workers by increasing the likelihood of conflict, longer hours and spillover effects.

(3) The effects of employee monitoring are ameliorated when employees have more autonomy, decision latitude and input into how monitoring is rolled out and implemented.

(4) The use of data generated by employee monitoring tools may be a useful resource for managers and health professionals to identify and promote well-being-oriented work practices, monitor working hours and identify issues around and predictors of presenteeism, overwork and exhaustion.

(5) The potential levers to address well-being issues include the adoption of more healthpromoting leadership behaviors, health and social interventions, increased managerial awareness of factors affecting employee well-being and organizational reviews of work design (including employee monitoring approaches) and work policies in collaboration with health professionals.

Effects of electronic monitoring 
IJWHM

15,3

404

\section{References}

Abraham, M., Niessen, C., Schnabel, C., Lorek, K., Grimm, V., Möslein, K. and Wrede, M. (2019), "Electronic monitoring at work: the role of attitudes, functions, and perceived control for the acceptance of tracking technologies", Human Resource Management Journal, Vol. 29 No. 4, pp. 657-675.

Adams, M. (2013), "Employees as a threat: developing effective performance monitoring systems", Doctoral Dissertation, Utica College.

Al-Hitmi, M. and Sherif, K. (2018), "Employee perceptions of fairness toward IoT monitoring", VINE Journal of Information and Knowledge Management Systems, Vol. 48 No. 4, pp. 504-516.

Alge, B.J. and Hansen, S.D. (2014), "Workplace monitoring and surveillance research since '1984': a review and agenda", in Coovert, M.D. and Foster Thompson, L.F. (Eds), The Psychology of Workplace Technology, Routledge, New York, pp. 209-237.

Allyn, B. (2020), "Your boss is watching you: work-from-home boom leads to more surveillance", available at: https://www.npr.org/2020/05/13/854014403/your-boss-is-watching-you-work-fromhome-boom-leads-to-more-surveillance?t=1601822936396 (accessed 12 February 2021).

Aloisi, A. and De Stefano, V. (2021), "Essential jobs, remote work and digital surveillance: addressing the COVID-19 pandemic panopticon”, International Labour Review, ePub, doi: 10.1111/ilr.12219.

Anderson, D. and Kelliher, C. (2020), "Enforced remote working and the work-life interface during lockdown", Gender in Management, Vol. 35 No. 7, pp. 677-683.

APA (2020), "Stress in America ${ }^{\text {TM }}$ 2020. Stress in the time of COVID-19, volume one", available at: https://www.apa.org/news/press/releases/stress/2020/report (accessed 12 February 2021).

Arora, P. and Suri, D. (2020), "Redefining, relooking, redesigning, and reincorporating HRD in the post Covid 19 context and thereafter", Human Resource Development International, Vol. 23 No. 4, pp. $438-451$.

Atanasoff, L. and Venable, M.A. (2017), "Technostress: implications for adults in the workforce”, The Career Development Quarterly, Vol. 65 No. 4, pp. 326-338.

Baer, M., Dhensa-Kahlon, R., Colquitt, J., Rodell, J.B., Outlaw, R. and Long, D. (2015), "Uneasy lies the head that bears the trust: the effects of feeling trusted on emotional exhaustion", Academy of Management Journal, Vol. 58 No. 6, pp. 1637-1657.

Baethge, A. and Rigotti, T. (2013), "Interruptions to workflow: their relationship with irritation and satisfaction with performance, and the mediating roles of time pressure and mental demands", Work and Stress, Vol. 27 No. 1, pp. 43-63.

Baker, M.G. (2020), "Nonrelocatable occupations at increased risk during pandemics: United States", American Journal of Public Health, Vol. 110 No. 8, pp. 1126-1132.

Bartels, L.K. and Nordstrom, C.R. (2012), "Examining big brother's purpose for using electronic performance monitoring", Performance Improvement Quarterly, Vol. 25 No. 2, pp. 65-77.

Bartmann, N., Cloughesy, J.N., Probst, B., Romagnoli, G. and Woerner, A. (2022), "Behavioural interventions to improve home-based office-workers' health", Trends in Psychology, Published online 13 January 2022, doi: 10.1007/s43076-021-00122-x (accessed 30 January 2022).

Bathini, D.R. and Kandathil, G.M. (2020), "Bother me only if the client complains: control and resistance in home-based telework in India”, Employee Relations, Vol. 42 No. 1, pp. 90-106.

Bernstrøm, V.H. and Svare, H. (2017), "Significance of monitoring and control for employees' felt trust, motivation, and mastery", Nordic Journal of Working Life Studies, Vol. 7 No. 4, pp. 29-49.

Bierema, L.L. (2020), "HRD research and practice after 'The great COVID-19 pause': the time is now for bold, critical, research", Human Resource Development International, Vol. 23 No. 4, pp. 347-360.

Bilotta, I., Cheng, S., Davenport, M.K. and King, E. (2021), "Using the job demands-resources model to understand and address employee well-being during the COVID-19 pandemic", Industrial and Organizational Psychology, Vol. 14 Nos 1-2, pp. 267-273. 
Biron, M., Peretz, H. and Turgeman-Lupo, K. (2020), “Trait optimism and work from home adjustment in the COVID-19 pandemic: considering the mediating role of situational optimism and the moderating role of cultural optimism", Sustainability, Vol. 12 No. 22, 9773, pp. 1-21.

Blanchard, C.M., Tremblay, M.A., Mask, L. and Perras, M.G.M. (2009), "A combination of work environment factors and individual difference variables in work interfering with family", International Journal of Workplace Health Management, Vol. 2 No. 1, pp. 63-90.

Blumenfeld, S., Anderson, G. and Hooper, V. (2020), "Covid-19 and employee surveillance", New Zealand Journal of Employment Relations, Vol. 45 No. 2, pp. 42-56.

Bolisani, E., Scarso, E., Ipsen, C., Kirchner, K. and John, P.H. (2020), "Working from home during COVID-19 pandemic: lessons learned and issues", Management and Marketing, Vol. 15, pp. 458-476.

Brandon Hall Group (2020), Transitioning to the New Realities of the COVID-19 Experience. Research Data Highlights (August 2020), Unpublished Internal Research Report, Brandon Hall Group.

Bulińska-Stangrecka, H., Bagieńska, A. and Iddagoda, A. (2021), "Work-life balance during COVID-19 pandemic and remote work: a systematic literature review", in Karanika-Murray, C.M., Biron, V., Hervieux, Z., Whysall, Z. and Chen, H. (Eds), Managing Presenteeism to Optimize Health and Performance. The SAGE Handbook of Organizational Wellbeing, Chapter 4, Sage, pp. 59-80.

Caligiuri, P., De Cieri, H., Minbaeva, D., Verbeke, A. and Zimmermann, A. (2020), "International HRM insights for navigating the COVID-19 pandemic: implications for future research and practice", Journal of International Business Studies, Vol. 51 No. 5, pp. 697-713.

Carnevale, J.B. and Hatak, I. (2020), "Employee adjustment and well-being in the era of COVID-19: implications for human resource management", Journal of Business Research, Vol. 116 No. 8, pp. 183-187.

Chang, K. and Smithikrai, C. (2010), "Counterproductive behaviour at work: an investigation into reduction strategies", The International Journal of Human Resource Management, Vol. 21 No. 8, pp. 1272-1288.

Cheng, X., Bao, Y. and Zarifis, A. (2020), "Investigating the impact of IT-mediated information interruption on emotional exhaustion in the workplace", Information Processing and Management, Vol. 57 No. 6, 102281, pp. 1-16.

Chillakuri, B. and Vanka, S. (2021), "Examining the effects of workplace well-being and highperformance work systems on health harm: a sustainable HRM perspective", Society and Business Review, Vol. 16 No. 1, pp. 71-93.

Cho, S., Kim, S., Chin, S.W. and Ahmad, U. (2020), "Daily effects of continuous ICT demands on workfamily conflict: negative spillover and role conflict", Stress and Health, Vol. 36 No. 4, pp. 533-545.

CIPD (2020), "Impact of COVID-19 on working lives. New findings and analysis on the ongoing impact of the coronavirus pandemic on working lives", available at: https://www.cipd.co.uk/ knowledge/work/trends/goodwork/covid-impact (accessed 12 February 2021).

Cooper, C.L., Flint-Taylor, J. and Pearn, M. (2013), Building Resilience for Success. A Resource for Managers and Organizations, Palgrave Macmillan, Basingstoke.

DeFilippis, E., Impink, S.M., Singell, M., Polzer, J.T. and Sadun, R. (2020), "Collaborating during Coronavirus: the impact of COVID-19 on the nature of work", NBER Working Paper No. 27612, July 2020, available at: https://www.nber.org/papers/w27612.pdf (accessed 12 February 2021).

Dewe, P. and Cooper, C. (2012), Well-being and Work, Palgrave Macmillan, Basingstoke.

Diab-Bahman, R. and Al-Enzi, A. (2020), "The impact of COVID-19 pandemic on conventional work settings", The International Journal of Sociology and Social Policy, Vol. 40 No. 9, pp. 909-927.

Dollard, M.F. and Bailey, T. (2021), "Building psychosocial safety climate in turbulent times: the case of COVID-19", Journal of Applied Psychology, Vol. 106 No. 7, pp. 951-964.

Dragano, N. and Lunau, T. (2020), "Technostress at work and mental health: concepts and research results", Current Opinion in Psychiatry, Vol. 33 No. 4, pp. 407-413.

Effects of electronic monitoring 
IJWHM

15,3

Eurofound (2020), Living, Working and COVID-19, COVID-19 Series, Publications Office of the European Union, Luxembourg, available at: https://www.eurofound.europa.eu/publications/ report/2020/living-working-and-covid-19 (accessed 12 February 2021).

Franke, F. (2015), "Is work intensification extra stress?”, Journal of Personnel Psychology, Vol. 14 No. 1, pp. 17-27.

Gallup (2021), State of the Global Workforce, Gallup, available at: https:/www.gallup.com/workplace/ 349484/state-of-the-global-workplace.aspx (accessed 25 September 2021).

Gorgenyi-Hegyes, E., Robert, J.N. and Fekete-Farkas, M. (2021), "Workplace health promotion, employee wellbeing and loyalty during Covid-19 pandemic-large scale empirical evidence from Hungary”, Economies, Vol. 9 No. 2, Article ID 55, pp. 1-22.

Groll, T. (2019), "Homeoffice-Arbeit bleibt die Ausnahme", Die Zeit, available at: https://www.zeit.de/ wirtschaft/2019-06/flexibles-arbeiten-homeoffice-anstieg-iab-studie (accessed 12 February 2021).

Gustavsson, R. and Söderlund, M. (2021), "The impact of remote work on performance monitoring”, Bachelor's Dissertation, Uppsala University, available at: https:/www.diva-portal.org/smash/ record.jsf?pid= diva2 $\% 3 \mathrm{~A} 1575044 \&$ dswid $=9404$.

Haines, V.Y., Marchand, A., Genin, E. and Rousseau, V. (2012), “A balanced view of long work hours”, International Journal of Workplace Health Management, Vol. 5 No. 2, pp. 104-119.

Hern, A. (2020), "Shirking from home? Staff feel the heat as bosses ramp up remote surveillance", The Guardian, available at: https:/www.theguardian.com/world/2020/sep/27/shirking-from-homestaff-feel-the-heat-as-bosses-ramp-up-remote-surveillance (accessed 12 February 2021).

Hill, S. (2020), "Corona-fied: employers spying on remote workers in their homes”, available at: https:// www.counterpunch.org/2020/09/24/corona-fied-employers-spying-on-remote-workers-in-theirhomes/ (accessed 12 February 2021).

Indiparambil, J.J. (2019), "Privacy and beyond: socio-ethical concerns of 'on-the-job' surveillance", Asian Journal of Business Ethics, Vol. 8 No. 1, pp. 73-105.

Ipsen, C., van Veldhoven, M., Kirchner, K. and Hansen, J.P. (2021), "Six key advantages and disadvantages of working from home in Europe during COVID-19", International Journal of Environmental Research and Public Health, Vol. 18 No. 4, Article ID 1826, pp. 1-17.

Jain, R., Rana, K.B. and Meena, M.L. (2021), "Association of individual and device usage factors with musculoskeletal disorders amongst handheld devices users during homestay due to pandemic", International Journal of Workplace Health Management, Vol. 14 No. 6, pp. 605-619.

Jamal, M.T., Anwar, I., Nawab, A.K. and Saleem, I. (2021), "Work during COVID-19: assessing the influence of job demands and resources on practical and psychological outcomes for employees", Asia - Pacific Journal of Business Administration, Vol. 13 No. 3, pp. 293-319.

Jeffery, C. (2020), "10 upsides to Covid-19 in changing how we work", Canadian HR Reporter, Vol. 33 No. 6 , p. 50.

Jeske, D. (2021), "Monitoring remote employees: implications for HR", Strategic HR Review, Vol. 20 No. 2, pp. $42-46$.

Jeske, D. and Santuzzi, A.M. (2015), "Monitoring what and how: psychological implications of electronic performance monitoring", New Technology, Work and Employment, Vol. 30 No. 1, pp. $62-78$.

Justesen, J.B., Eskerod, P., Christensen, J.R. and Sjøgaard, G. (2017), "Implementing workplace health promotion - role of middle managers", International Journal of Workplace Health Management, Vol. 10 No. 2, pp. 164-178.

Kalischko, T. and Riedl, R. (2021), "Electronic performance monitoring in the digital workplace: conceptualization, review of effects and moderators, and future research opportunities", Frontiers in Psychology, ePub, Vol. 12, 633031, doi: 10.3389/fpsyg.2021.633031.

Kane, G.C., Nanda, R., Phillips, A. and Copulsky, J. (2021), "Redesigning the post-pandemic workplace", MIT Sloan Management Review, Vol. 62 No. 3, pp. 12-14. 
Kniffin, K.M., Narayanan, J., Anseel, F., Antonakis, J., Ashford, S.P., Bakker, A.B., Bamberger, P., Bapuji, H., Bhave, D.P., Choi, V.K., Creary, S.J., Demerouti, E., Flynn, F.J., Gelfand, M.J., Greer, L.L., Johns, G., Kesebir, S., Klein, P.G., Lee, S.Y., Ozcelik, H., Petriglieri, J.L., Rothbard, N.P., Rudolph, C.W., Shaw, J.D., Sirola, N., Wanberg, C.R., Whillans, A., Wilmot, M.P. and van Vugt, M. (2021), "COVID-19 and the workplace: implications, issues, and insights for future research and action", American Psychologist, Vol. 76 No. 1, pp. 63-77.

Koch, J. and Schermuly, C. (2021), "Managing the crisis: how Covid-19 demands interact with agile project management in predicting employee exhaustion", British Journal of Management, Vol. 32 No. 4, pp. 1265-1283.

Koekemoer, L., de Beer, L.T., Govender, K. and Brouwers, M. (2021), "Leadership behaviour, team effectiveness, technological flexibility, work engagement and performance during COVID-19 lockdown: an exploratory study", SA Journal of Industrial Psychology, ePub, Vol. 47, a1829, doi: 10.4102/sajip.v47i0.1829.

Laird, B.K., Bailey, C.D. and Hester, K. (2018), "The effects of monitoring environment on problemsolving performance", The Journal of Social Psychology, Vol. 158 No. 2, pp. 215-219.

Liu, L., Zhang, C. and Fang, C.-C. (2021), "Effects of health-promoting leadership, employee health on employee engagement: employability as moderating variable", International Journal of Workplace Health Management, Vol. 15 No. 1, pp. 1-18.

Lockwood, G. and Nath, V. (2021), "The monitoring of tele-homeworkers in the UK: legal and managerial implications", International Journal of Law and Management, Vol. 63 No. 4, pp. 396-416.

Lyra Health (2020), "American worker in crisis: understanding employee mental health in unprecedented times", Report issued in July 2020 by Lyra Health in Collaboration with the National Alliance of Healthcare Purchaser Coalitions, USA, available at: https://www. lyrahealth.com/wp-content/uploads/2020/07/LYRA-NA-Employee-Mental-Health-Report.pdf (accessed 12 February 2021).

McDaniel, B.T., O'Connor, K. and Drouin, M. (2021), "Work-related technoference at home and feelings of work spillover, overload, life satisfaction and job satisfaction", International Journal of Workplace Health Management, Vol. 14 No. 5, pp. 526-541.

McEvoy, F.J. (2020), "Employee surveillance doesn't increase productivity - it's demotivating”, available at: https://anotherfn.com/2020/06/16/employee-surveillance-doesnt-increaseproductivity-its-demotivating-the-next-web-anotherfn-com/ (accessed 12 February 2021).

Mallett, O., Marks, A. and Skountridaki, L. (2020), "Where does work belong anymore? The implications of intensive homebased working", Gender in Management, Vol. 35 No. 7, pp. 657-665.

Martin, A.J., Wellen, J.M. and Grimmer, M.R. (2016), “An eye on your work: how empowerment affects the relationship between electronic surveillance and counterproductive work behaviours", The International Journal of Human Resource Management, Vol. 27 No. 21, pp. 2635-2651.

Martin, A., Woods, M. and Dawkins, S. (2018), "How managers experience situations involving employee mental ill-health", International Journal of Workplace Health Management, Vol. 11 No. 6, pp. 442-463.

Mellor, N. and Webster, J. (2013), "Enablers and challenges in implementing a comprehensive workplace health and well-being approach", International Journal of Workplace Health Management, Vol. 6 No. 2, pp. 129-142.

Mojtahedzadeh, N., Rohwer, E., Lengen, J., Harth, V. and Mache, S. (2021), "Health-promoting work design for telework in the context of the COVID-19 pandemic", Zentralblatt für Arbeitsmedizin, Arbeitsschutz und Ergonomie, Vol. 71 No. 2, pp. 69-74.

Morrison, S. (2020), “Just because you're working from home doesn't mean your boss isn't watching you. Software that monitors remote employees is seeing a sales boom", Vox.com, available at: https://www.vox.com/recode/2020/4/2/21195584/coronavirus-remote-work-from-homeemployee-monitoring (accessed 12 February 2021).

Effects of electronic monitoring 
IJWHM 15,3

408

National Safety Council (2021), "Promote employee mental health and wellbeing", National Safety Council, available at: https://www.nsc.org/work-safety/safety-topics/coronavirus/mental-healthand-wellbeing (accessed 12 February 2021).

O'Connell, B. (2020), "How managers are handling performance reviews during the COVID-19 pandemic", Society of Human Resource Management, available at: https://www.shrm.org/ resourcesandtools/hr-topics/people-managers/pages/performance-reviews-during-coronavirus-. aspx (accessed 12 February 2021).

Pachler, D., Kuonath, A., Specht, J., Kennecke, S., Agthe, M. and Frey, D. (2018), "Workflow interruptions and employee work outcomes: the moderating role of polychronicity", Journal of Occupational Health Psychology, Vol. 23 No. 3, pp. 417-427.

Park, Y., Liu, Y. and Headrick, L. (2020), "When work is wanted after hours: testing weekly stress of information communication technology demands using boundary theory", Journal of Organizational Behavior, Vol. 41 No. 6, pp. 518-534.

Passetti, E.E., Battaglia, M., Bianchi, L. and Annesi, N. (2021), "Coping with the COVID-19 pandemic: the technical, moral and facilitating role of management control", Accounting, Auditing and Accountability Journal, Vol. 34 No. 6, pp. 1430-1444.

Pierce, B.S., Perrin, P.B., Tyler, C.M., McKee, G.B. and Watson, J.D. (2021), "The COVID-19 telepsychology revolution: a national study of pandemic-based changes in US mental health care delivery", American Psychologist, Vol. 76 No. 1, pp. 14-25.

Ravid, D.M., Tomczak, D.L., White, J.C. and Behrend, T.S. (2020), "EPM 20/20: a review, framework, and research agenda for electronic performance monitoring", Journal of Management, Vol. 46 No. 1, pp. 100-126.

Rees, G. (2020), "Employee-monitoring technology: productivity vs privacy", available at: https://www. intheblack.com/articles/2020/09/01/employee-monitoring-technology-productivity-privacy (accessed 12 February 2021).

Sarmah, A.K. and Chaudhuri, P. (2021), "New role of human resource development in Covid-19 crisis", Parikalpana: KIIT Journal of Management, Vol. 17 No. 1, pp. 283-291.

Shaffer, J. and Darnold, T. (2020), "HR practices and counterproductive behaviors: a metaethnographic study", Journal of Managerial Psychology, Vol. 35 Nos 7/8, pp. 589-602.

Sherif, K., Jewesimi, O. and El-Masri, M. (2021), "Empowering employees: the other side of electronic performance monitoring", Journal of Information, Communication and Ethics in Society, Vol. 19 No. 2, pp. 207-221.

Siegel, R., König, C.J. and Leon Porsch, L. (2021), "Does electronic monitoring pay off?", Journal of Personnel Psychology, Vol. 20 No. 3, pp. 103-113.

Sinclair, R.R., Allen, T., Barber, L., Bergman, M., Britt, T., Butler, A., Ford, M., Hammer, L., Kath, L., Probst, T. and Yuan, Z. (2020), "Occupational health science in the time of COVID-19: now more than ever", Occupational Health Science, Vol. 4 Nos 1-2, pp. 1-22.

Spagnoli, P., Molino, M., Molinaro, D., Giancaspro, M.L., Manuti, A. and Ghislieri, C. (2020), "Workaholism and technostress during the COVID-19 emergency: the crucial role of the leaders on remote working”, Frontiers in Psychology, Vol. 11, 620310, pp. 1-9.

Tavani, H.T. (2004), Ethics and Technology: Ethical Issues in an Age of Information and Communication Technology, John Wiley \& Sons, Chichester.

Tomczak, D.L., Lanzo, L.A. and Aguinis, H. (2018), "Evidence-based recommendations for employee performance monitoring”, Business Horizons, Vol. 61 No. 2, pp. 251-259.

Tomczak, D.L., Behrend, T.S., Willford, J. and Jimenez, W.P. (2020), “I didn't agree to these terms': electronic performance monitoring violates the psychological contract", available at: https:// psyarxiv.com/qax9u/.

Tyler, K. (2021), "How to ride the great resignation wave", SHRM, available at: https://www.shrm.org/ hr-today/news/hr-magazine/summer2021/pages/reducing-turnover.aspx (accessed 25 September 2021). 
Vatcha, A. (2020), "Workplace surveillance outside the workplace: an analysis of e-monitoring remote employees", iSChannel, Vol. 15 No. 1, pp. 4-9.

Wandt, J. (2020), Nach sechs Monaten im Homeoffice: Wie Beschäftigte die Situation einschätzen, Study summary from the University Konstanz, published the Idw - Informationsdienst Wissenschaft, available at: https://idw-online.de/de/news757746 (accessed 12 February 2021).

Wang, B., Schlagwein, D., Cecez-Kecmanovic, D. and Cahalane, M.C. (2020), "Editorial: beyond the factory paradigm: digital nomadism and the digital future(s) of knowledge work post-COVID-19", Journal of the Association for Information Systems, Vol. 21 No. 6, pp. 1379-1401.

Wang, B., Liu, Y., Qian, J. and Parker, S.K. (2021), "Achieving effective remote working during the Covid-19 pandemic: a work design perspective”, Applied Psychology, Vol. 70 No. 1, pp. 16-59.

Welter, L.M. and Ensslin, S.R. (2021), "How do the unintended consequences of performance evaluation systems manifest themselves?", Journal of Accounting and Organizational Change, article published online on 4 August 2021, in press, doi: 10.1108/JAOC-07-2020-0087.

Wigert, B. and Barrett, H. (2020), Performance Management Must Evolve to Survive COVID-19, Gallup, available at: https://www.gallup.com/workplace/318029/performance-managementevolve-survive-covid.aspx (accessed 12 February 2021).

Wilkie, D. (2020), "Workers' mental health suffers during the pandemic: how managers can help", Society of Human Resource Management, available at: https://www.shrm.org/ resourcesandtools/hr-topics/people-managers/pages/covid-and-mental-health-.aspx (accessed 12 February 2021).

Wyatt, A. (2020), "How corporate fitness programs are shifting in a work-from-home world", HR Daily Advisor, available at: https://hrdailyadvisor.blr.com/2020/04/22/how-corporate-fitnessprograms-are-shifting-in-a-work-from-home-world/ (accessed 11 September 2021).

Yost, A.B., Behrend, T.S., Howardson, G., Darrow, J.B. and Jensen, J.M. (2019), "Reactance to electronic surveillance: a test of antecedents and outcomes", Journal of Business and Psychology, Vol. 34 No. 1, pp. 71-86.

Zhou, Y., MacGeorge, E.L. and Myrick, J.G. (2020), "Mental health and its predictors during the early months of the COVID-19 pandemic experience in the United States", International Journal of Environmental Research and Public Health, Vol. 17 No. 17, Article 6315, pp. 1-19.

\section{Corresponding author}

Debora Jeske can be contacted at: d.jeske@ucc.ie

For instructions on how to order reprints of this article, please visit our website:

www.emeraldgrouppublishing.com/licensing/reprints.htm

Or contact us for further details: permissions@emeraldinsight.com 